\title{
Lighting Research and Technology
}

\section{Daylighting: appraisal at the early design stages \\ H. Byrd and A. Hildon}

Lighting Research and Technology 1979 11: 99

DOI: $10.1177 / 14771535790110020301$

The online version of this article can be found at:

http://rt.sagepub.com/content/11/2/99

\author{
Published by: \\ (3)SAGE \\ http://www.sagepublications.com
}

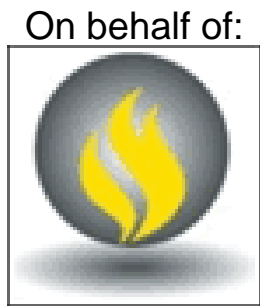

The Society of Light and Lighting

Additional services and information for Lighting Research and Technology can be found at:

Email Alerts: http://lrt.sagepub.com/cgi/alerts

Subscriptions: http://lrt.sagepub.com/subscriptions

Reprints: http://www.sagepub.com/journalsReprints.nav

Permissions: http://www.sagepub.com/journalsPermissions.nav

Citations: http://rt.sagepub.com/content/11/2/99.refs.html

>> Version of Record - Jun 1, 1979

What is This? 
Summary A method for analysing daylight in buildings is described for use in the early stages of the design process where the conflicting functions of the window can be related through a knowledge of the percentage glazing on a building facade.

\title{
Daylighting: appraisal at the early design stages
}

\author{
H. BYRD, BA(Arch.), AND A. HILDON, BA, PhD(Cantab)
}

\section{Introduction}

For a building design team concerned with the quality of the internal environment of buildings the percentage area of glazing on a building facade is one of the most useful criteria for judging the building envelope as a modifier of climate at early design stages, since it is at the window that the various environmental parameters (heat, light and sound) remain only minimally modified.

The percentage area of glazing can be used to relate the numerous and often conflicting functions of the window such as the provision of daylight, summertime temperatures ${ }^{1}$, sound insulation ${ }^{2}$, energy efficiency ${ }^{3}$ and view satisfaction ${ }^{4}$.

\section{Predicting daylight}

Although several well established techniques for predicting daylight conditions within rooms already exist 5 these are not compatible with the conjectural processes of the early design stages.

This is in common with other forms of environmental predictive techniques where high precision, inflexibility, time consumption and other properties result in their non-use at the critical stages in the generation of building form 6,7 . The designer requires techniques that are essentially 'rules of thumb' to guide and influence decisions made during the conjectural stages of design, the importance and value of such simple and flexible methods being more important than the loss of precision involved ${ }^{8}$. The method described here allows an analysis of daylighting to be done at early design stages and relates the minimum daylight factor (that daylight factor equalled or exceeded over the working plane) to the percentage area of glazing,

H. Byrd is a research student and A. Hildon, Principal lecturer in architectural science at the Birmingham School of Architecture, City of Birmingham Polytechnic. The paper was first received on 19 March 1979, and in revised form on 11 May 1979. depending on room geometry and reflectance. It also allows the uniformity of daylight distribution within the room to be analysed and can yield the area over which supplementary lighting is required if daylighting is inadequate.

\section{$3 \quad$ Criteria for daylighting design}

There are essentially three principal criteria for assessing the quantity of daylight within rooms. These are the daylight factor at any point (sky and internally reflected components), the minimum daylight factor and average daylight factor. In terms of accuracy there is little to choose between the different predictive methods but the minimum and average daylight factors are more useful criteria at early design stages as they measure properties of a room rather than any point within a room.

The advantages of the average daylight factor are that it bears a close relationship with the subjective appraisal of lighting in a room ${ }^{9}$ and it is less sensitive to changes in the sky luminance distribution and the positioning of the window in the window-wall. However, while recommendations for daylighting are related to minimum standards applicable to the whole room a knowledge of the minimum daylight factor is important particularly where task lighting is considered.

The main argument against the minimum daylight factor as a design criterion is that by concentrating on achieving adequate amounts of light furthest from the window it can lead to over-fenestration with its attendant problems such as glare, excessive heat losses and gains. However the minimum daylight factor does have advantages where task lighting is required if it is not taken as a criterion in itself but is considered alongside the distribution of daylight in a room through an assessment of uniformity.

The method presented here (Fig. 1) is empirically based and employs the minimum daylight factor as the design criterion. The upper part of the graph relates the minimum daylight factor to the window : floor area ratio for various conditions of 


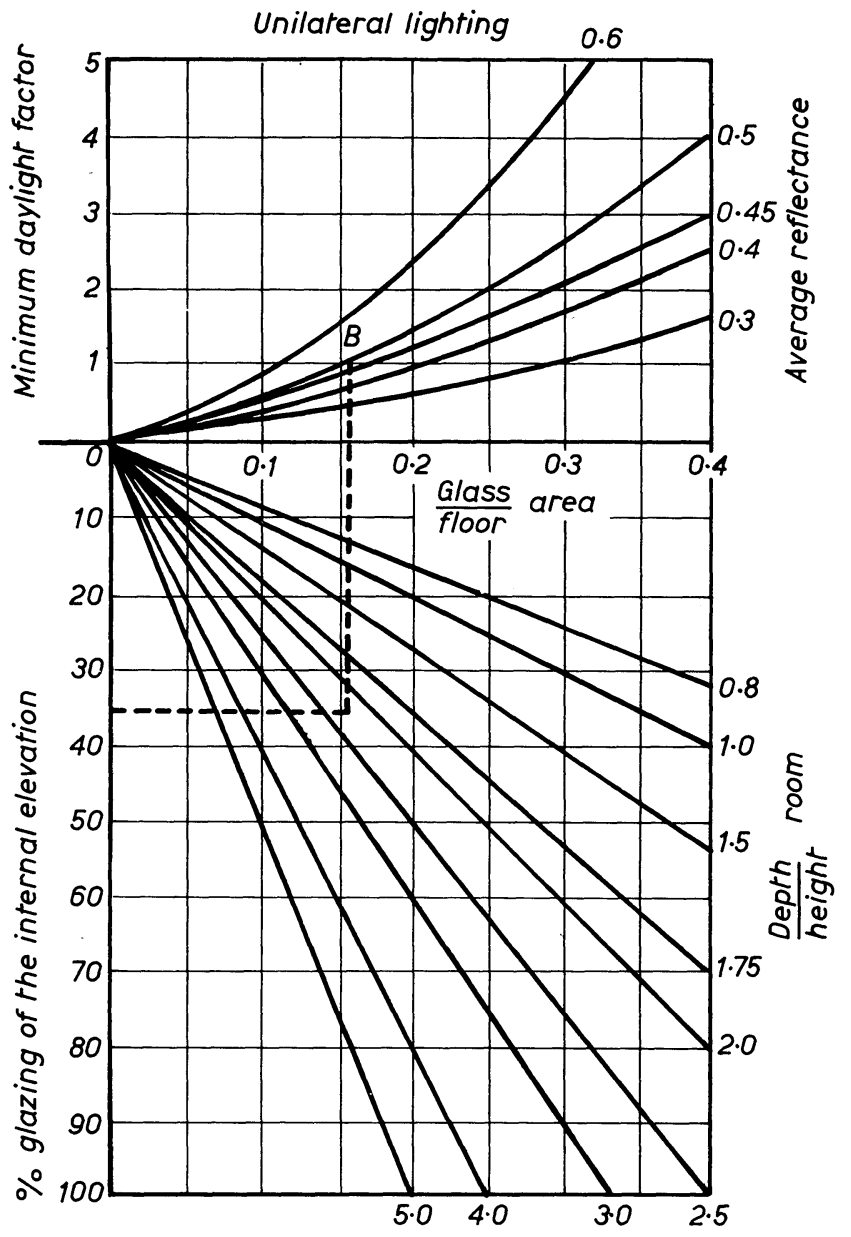

Fig. 1. The minimum daylight factor related to per cent area of glazing of the internal elevation of the window wall.

room reflectance. The lower part of the graph simply relates the window: floor area to the percentage glazing through a knowledge of room geometry.

To complete this method a rule of thumb for assessing uniformity is incorporated.

\section{Uniformity of daylighting}

Uniformity is essentially a measure of the subjective appraisal of lighting within a room but it is also a measure of efficiency of providing adequate lighting levels without over-glazing. For example, a room may have the required minimum daylight factor but if this is achieved only by an excessive window area then the room may be too deep or dark. The uniformity of daylighting can be measured as the ratios of minimum: average or minimum: maximum daylight factor, although Lynes ${ }^{10}$ has produced a formula for the ratio of average daylight factor in the front half of the room: average daylight factor in the back half of the room. The rule of thumb described here uses the ratio of minimum: maximum with a limiting value of $1: 10$ as this is near the maximum acceptable contrast. The minimum daylight factor is a known quantity (from Fig. 1) and the maximum is easily deduced as it has a constant relationship with the percentage glazing being relatively independent of room conditions. The maximum daylight factor is taken as being $1 \mathrm{~m}$ from the window and although this is not a true maximum it covers an area more closely representative of the subjective maximum and has an approximate value of ten times the window height (metres), assuming the cill level to be on the working plane.

Maximum DF: Minimum DF $<10$

$\operatorname{Max} \mathrm{DF}=10 \mathrm{~h}$

$$
\frac{\mathrm{g}}{100}=\frac{\mathrm{w} \cdot \mathrm{h}}{\mathrm{W} \cdot \mathrm{H}}
$$

$$
\begin{aligned}
& \text { From (1), (2) \& (3) } \\
& \frac{\mathrm{g}}{\min \mathrm{DF}}<100 \cdot \frac{\mathrm{w} \cdot 1}{\mathrm{~W} \cdot \mathrm{H}}
\end{aligned}
$$

where

$$
\begin{aligned}
& \mathrm{g}=\text { percentage area glazing } \\
& \mathrm{W}=\text { window width } \\
& \mathrm{h}=\text { window height (metres) } \\
& \mathrm{W}=\text { room width } \\
& \mathrm{H}=\text { room height }
\end{aligned}
$$

For typical ceiling heights and positioning of windows the limiting value for acceptable uniformity is

$$
\frac{\% \text { glazing }}{\text { Min DF }}<30
$$

Even if adequate daylighting is provided the ratio for uniformity may be checked taking the values of minimum daylight factor and percentage glazing from the graph, and if the ratio is excessive then the necessary changes in room geometry and/or reflectance can be quickly calculated.

\section{Graphical method}

The graph (Fig. 1) consists essentially of four parameters; the minımum daylight factor, the area weighted average reflectance, the Depth: Height ratio of the room and the percentage area of glazing of the window wall. A knowledge of any three will determine the fourth but its most common uses will be for determining percentage glazing or maximum depth of a room for given lighting levels and room conditions. The latter use is particularly relevant to supplementary lighting. The predicted depth of adequate daylighting can be compared with the actual depth of the room and hence the difference will yield the depth of the room requiring supplementary lighting. This may also provide useful data for selective switching or dimming of artificial lighting systems although ultimately other values of sky luminance distribution must be used for a better assessment. This method is intended to be used for integrating those factors involved in producing a building that not only modifies climate for comfort reasons but also for efficient use of energy. While the new building regulations part $\mathrm{FF}^{11}$ may seem heavy handed in restricting glazing they do set targets which can easily be applied to this method, although there can be a trade-off if multiple glazing or rooflights are used.

For example: a typical office of average reflectance 0.5 requires a minimum daylight factor of 1 per cent. If single glazing is to be used and there are no rooflights then the maximum percentage glazing 
permitted is 35 per cent if it is to conform to part $\mathrm{FF}$ of the building regulations. 35 per cent can therefore be flagged (A) on Fig. 1.

The intersection of 1 per cent minimum daylight factor with the 0.5 reflectance curve can also be located (B). Where the horizontal from A meets the vertical from $B$ the maximum Depth: Height of the room can be read (2.25). If the ceiling height is $3 \mathrm{~m}$ then the maximum depth of the room is $6.75 \mathrm{~m}$ if it is to achieve a 1 per cent minimum daylight factor

Similarly, if the Depth: Height ratio is already determined then the percent glazing required to provide the specified minimum daylight factor in the room can be found and checked against other design targets. For instance, checking for uniformity; the ratio (equation 5 ) will be exceeded for the above example $(35: 1)$. By altering the room geometry or reflectance the percentage glazing may be reduced. In this example, if the depth of the room is decreased to $6 \mathrm{~m}$ or the reflectance increased to 0.55 then only 30 per cent glazing is required which satisfies the uniformity ratio.

\section{Conclusion}

In conclusion: the average daylight factor will provide the best criteria for assessing daylighting within a room but only when its method of calculation and recommended values have been agreed upon. But the minimum daylight factor will always remain a useful criterion where task lighting is required.

\section{Acknowledgement}

The authors are grateful to A. J. Howrie, Head of Department, for the provision of research facilities and encouragement. H. Byrd is funded by the Science Research Council.

\section{References}

1 Loudon, A. G., Summertime temperatures in buildings, BRS current paper 47/68 (1968).

2 British Standard Institution, Code of Practice, B.S. C. P. 3 Chapter III (1960).

3 Burberry, P., Building for energy conservation, (Architectural Press, London, 1978).

4 Keighley, E. C., Visual requirements and reduced fenestration in offices. B. R.E. current paper 41/74 (1974).

5 International recommendations for the calculation of natural daylight. CIE publication No. 16 (1970).

6 Predictive techniques in the design process: a survey. Birmingham School of Architecture, Internal Report (1978).

7 Croghan, D. \& Hawkes, D., Daylighting in dwellings 3 Archit. J., 26 Feb (1969).

8 Koenigsberger, O., Archit. Sci. Rev. 21, 6 (1978).

9 Longmore, J., Daylighting-a current view, Light Ltg. 68, 113, (1975).

10 Lynes, J. A., Ltg Res. \& Technol, this issue p 102

11 The Building Regulations (first amendment) 1978 part FF. 